\title{
Transplante de células tronco hematopoéticas para doenças auto-imunes no Brasil
}

\author{
Júlio C. Voltarelli
}

\begin{abstract}
O transplante de células progenitoras hematopoéticas apresenta bases sólidas para ser indicado no tratamento das doenças autoimunes. No relato são apresentados estes dados e a seqüência de eventos que tem contribuído para a implantação de um protocolo brasileiro do procedimento na modalidade autogênica utilizando regimes de mobilização uniforme com Ciclofosfamida $2 \mathrm{~g} / \mathrm{m}^{2}$ mais fator estimulador de colônias granulocitárias e condicionamentos particulares para o lúpus eritematoso sistêmico, esclerose sistêmica e esclerose múltipla. As entidades descritas anteriormente foram escolbidas para o início do protocolo cooperativo após amplos debates em encontros ocorridos em Ribeirão Preto e São Francisco, EUA.
\end{abstract}

Rev.bras.hematol.hemoter., 2002, 24(1): 9-13

Palavras-chaves: Doenças auto-imunes, transplante de células progenitoras, tratamento

\section{Introdução}

A aplicação do transplante de células tronco hematopoéticas (TCTH) no tratamento de doenças auto-imunes (DAI) graves e refratárias possui sólidas bases experimentais e clínicas (13). Desde a década de 70, o sucesso desta abordagem terapêutica foi amplamente demonstrado em modelos animais de DAI e em pacientes portadores dessas doenças que foram transplantados para hemopatias concomitantes. O primeiro transplante isolado para uma DAI (na síndrome de CREST, uma variante da esclerose sistêmica) foi relatado por Tamm e colaboradores do grupo da Basiléia, Suíça, em 1996 e, desde então, centenas de pacientes foram transplantados, em estudos-piloto de fase I/II, com resultados bastante animadores.
Atualmente, estão se iniciando, na Europa e nos EUA, protocolos clínicos prospectivos randomizados (de fase III) comparando o TCTH com a melhor terapia convencional disponível. A grande maioria desses transplantes emprega CTH periféricas autólogas mobilizadas da medula óssea e purificadas em colunas de seleção (positiva ou negativa) contendo anticorpos monoclonais contra subpopulações celulares. As DAI mais frequentemente tratadas com TCTH são a esclerose múltipla (EM), a esclerose sistêmica (ES), o lúpus eritematoso sistêmico (LES), a artrite reumatóide (AR), as citopenias auto-imunes e as vasculites sistêmicas, mas têm sido criados protocolos para várias outras doenças, incluindo a doença de Crohn, os pênfigos e o diabetes melito.

Apesar do grande entusiasmo existente

Coordenador da Unidade de Transplante de Medula Óssea do Hospital das Clinicas da Faculdade de Medicina de Ribeirão Preto da Universidade de São Paulo (HC-FMRPUSP) e do Protocolo Cooperativo Brasileiro de Transplante de Células Tronco Hematopoéticas em Doenças Auto-imunes

Correspondência para: Júlio Cesar Voltarelli

Hospital das Clínicas da Faculdade de Medicina de Ribeirão Preto-Campus USP

Unidade de TMO - 5o andar

Ribeirão Preto,SP. CEP: 14048-900. E-mail: jcvoltar@fmrp.usp.br 
atualmente por esta modalidade terapêutica, várias de suas propriedades, além da eficiência clínica a longo prazo, precisam ser determinadas em estudos controlados e randomizados, que só agora começam a ser desenvolvidos: iniciando pelo papel das CTH infundidas e da imunoablação, a determinação do melhor tipo de transplante (auto, alo ou mini-alo), a necessidade de depleção de células $\mathrm{T}$ e $\mathrm{B}$ contaminantes do enxerto, os melhores esquemas de mobilização e de condicionamento, entre outros aspectos, demandarão longos anos de estudos clínicos e laboratoriais. Temos todas as condições, em nosso país, de participar deste esforço que está mobilizando a comunidade científica internacional.

Entretanto, a organização de um programa de TCTH para DAI no Brasil, presumivelmente, poderá esbarrar em várias dificuldades típicas do nosso desenvolvimento sócio-econômico heterogêneo: financiamento insuficiente pelos sistemas público e securitário de saúde, competição por espaço com os transplantes tradicionais, falta de recursos rotineiros em países desenvolvidos (como as colunas para seleção de CTH) e o baixo nível cultural e econômico dos pacientes. Por outro lado, além dessas dificuldades não serem insuperáveis, elas são contrabalançadas por características peculiares que tornam esses transplantes altamente vantajosos de serem realizados em nosso país: nossa grande experiência com o transplante de DAIs hematológicas, como a anemia aplástica (5), maior gravidade das DAIs em populações de nível mais baixo, como a nossa, cobertura universal de tratamentos complexos para a população de baixa renda e grande disponibilidade de doadores familiares HLA-idênticos nas famílias brasileiras (no caso de se planejarem protolocos de transplantes alogênicos subablativos, por exemplo).

Previamente à organização dos protocolos brasileiros de TCTH para DAI, temos conhecimento de dois pacientes portadores de DAI isolada, transplantados no Brasil: um portador de crioaglutinina produzindo vasculite cutânea e anemia hemolítica, transplantado no Hospital Albert Einstein-SP em 1996, com boa evolução (6) e outro, portador de esclerose sistêmica, transplantado na PUC-RGS, evoluindo 1 ano após, para óbito por infecção (von Muhlen, comunicação pessoal).

\section{Os protocolos brasileiros}

Em outubro de 2000, organizamos um simpósio internacional em Ribeirão Preto para discutirmos, em um ambiente informal e bastante crítico, a implantação de um protocolo cooperativo nacional de HSCT em DAI. Compareceram ao simpósio representantes dos principais grupos de TMO do Brasil, ao lado de reumatologistas, nefrologistas e neurologistas de vários centros brasileiros e quatro especialistas internacionais com grande experiência neste tipo de transplantes - Richard Burt de Chicago, William Burns de Milwaukee, Dhaval Patel, de Durham e Renate Arnold, de Berlim - além de um especialista em seleção de CTH por citometria de fluxo, Dennis Sasaki de San Diego. Propusemos, no evento, o início de um protocolo randomizado de fase III, tratando pacientes portadores de LES refratários à terapia convencional com alta dose de ciclofosfamida (200 mg/kg) alocando-os aleatoriamente para receber ou não suporte de CTH autólogas.

Este protocolo objetivava abordar cientificamente o efeito das CTH, em adição à imunoablação, no tratamento agressivo das DAÍ. A maioria dos participantes do encontro desaconselhou esta abordagem e sugeriu a adoção de protocolos-piloto mais conservadores, para se ganhar experiência na área, em estudos de fase I/II. Foram selecionadas, assim, três doenças, o LES, a ES e EM para o início do programa, com mesmo regime de mobilização de $\mathrm{CTH}$, mas com indicações e regimes de condicionamento específicos para cada uma delas. Para substituir a depleção in vitro de células T nas colunas de seleção de CTH, foi decidido fazer depleção in vivo com globulina anti-timocitária (ATG), disponível comercialmente, ao invés das colunas de seleção. Os membros dos grupos de TMO interessados no programa se reuniram pela segunda vez durante encontro da Sociedade 
Americana de Hematologia (ASH), em São Francisco - EUA, em dezembro de 2000, onde aspectos adicionais do protocolo, como o esquema de administração de ATG, foram discutidos e acordados.

Subsequentemente, protocolos detalhados para cada uma das doenças escolhidas foram desenvolvidos com o auxílio substancial dos colegas Paulo Lousada Jr., imunologista clínico do HCFMRP, que contribuiu para o protoloco de LES, Nelson Hamerschlak e Andreza Ribeiro, hemato-oncologistas e Charles Tilbery, neurologista, do Hospital Albert Einstein-SP, que contribuíram na EM e Luís Eduardo de Andrade, da Unifesp e João Francisco Marques Neto, da Unicamp, reumatologistas que colaboraram na ES (vide tabela em anexo e ref. 7).

Vários grupos de TMO submeteram, então, esses protocolos a suas comissões institucionais de ética em pesquisa, tendo sido realizado o primeiro transplante do programa em junho/ 2001, no Hospital Albert Einstein, em São Paulo, em uma paciente portadora de esclerose múltipla, que teve alta no $\mathrm{D}+14$ sem complicações e encontra-se atualmente em fisioterapia, melhorando gradativamente de seus problemas neurológicos (fraqueza muscular e disfunção esfinctérica). Em setembro, transplantamos no HCFMRP um paciente de 26 anos, portador de síndrome nefrótica secundária a LES, refratária a sete pulsos mensais de ciclofosfamida.

Após várias complicações da mobilização e do condicionamento, que incluíram quadros infecciosos, insuficiência renal pós-ATG e cistite hemorrágica, o paciente teve alta no D+32 e, dois meses após o transplante, obteve uma significativa melhora da doença renal (redução da proteinúria diária de $12 \mathrm{~g}$ para $0,8 \mathrm{~g}$ e aumento da albumina sérica de 1,5 para $4,0 \mathrm{~g} /$ dl), que se mantém após 6 meses sem imunossupressão. Um outro paciente, de 12 anos de idade, portador de uma síndrome de superposição (LES + ES) foi mobilizado e faleceu por ativação de vasculite.

O desafio atual do programa é promover um entrosamento mais eficiente entre os grupos de reumatologia/nefrologia/neurologia com os de TMO e iniciar, efetivamente, os transplantes nos vários centros interessados, entre os quais se incluem os hospitais universitários da UFRJRio de Janeiro, da UNIFESP-São Paulo, da UFMGBelo Horizonte, da UNICAMP-Campinas, da UFRGS e da PUC-Porto Alegre e da FAMERPSão José do Rio Preto. Para isto, é necessário superar, além dos problemas peculiares a nossa realidade, apontados acima, barreiras logísticas, como a dificuldade de entrosamento entre as equipes de TMO e as dos especialistas pela assistência aos casos de DAI e a sua resistência

\section{Protocolos-piloto de TCTH autólogo não-manipulado para DAI no Brasil}

\begin{tabular}{|l|l|l|l|l|}
\hline Doença & Inclusão* & Mobilização & Condicionamento & Observações \\
\hline LES & $\begin{array}{l}\text { Nefrite, vasculite } \\
\text { sistêmica, citopenias, } \\
\text { sindr. anti-fosfolípide }\end{array}$ & $\begin{array}{l}\text { CY } 2 \mathrm{~g} / \mathrm{m}^{2}+ \\
\text { G-CSF }\end{array}$ & $\begin{array}{l}\text { CY } 200 \mathrm{mg} / \mathrm{kg}+ \\
\text { ATG } 90 \mathrm{mg} / \mathrm{kg}\end{array}$ & $\begin{array}{l}\text { Baseado na experiência } \\
\text { européia e americana } \\
(1,2,3,8)\end{array}$ \\
\hline ES & $\begin{array}{l}\text { Doença pulmonar } \\
\text { progressiva }\end{array}$ & Idem & $\begin{array}{l}\text { CY } 120 \mathrm{mg} / \mathrm{kg}+ \\
\text { ATG } 90 \mathrm{mg} / \mathrm{kg} / \mathrm{d}+ \\
\text { FLU } 120 \mathrm{mg} / \mathrm{kg}\end{array}$ & $\begin{array}{l}\text { Condicionamento } \\
\text { inédito p/ ES, mas } \\
\text { usado em mini-alo } \\
\text { e em EM (9, 10) }\end{array}$ \\
\hline EM & $\begin{array}{l}\text { Formas } \\
\text { progressivas }\end{array}$ & Idem & BEAM + ATG & $\begin{array}{l}\text { Baseado no consenso } \\
\text { europeu (11) }\end{array}$ \\
\hline
\end{tabular}

*Apenas pacientes que falharam à melhor terapia convencional disponível

LES: lúpus eritematoso sistêmico, ES: esclerose sistêmica, EM: esclerose múltipla, AR: artrite reumatóide, CY: ciclofosfamida, ATG: globulina anti-timocitária, G-CSF: fator estimulador de colônias granulocitárias, FLU: fludarabina, BEAM: BCNU, etoposído, aracytin e melfalan 
ao encaminhamento de pacientes para transplante.

Essas barreiras serão, certamente, superadas quando os primeiros transplantes forem realizados e seus resultados divulgados, tanto na comunidade médica como na sociedade. Nossa instituição, por exemplo, já está mobilizada para criar uma Unidade de isolamento especificamente destinada aos transplantes em DAI, separada dos onco-hematológicos, e temos recebido, a exemplo de outras instituições nacionais, um grande número de consultas de pacientes interessados no procedimento. Apesar da maioria dessas consultas não resultar em indicações concretas para o transplante, elas ilustram, nesta fase inicial de implantação do programa, o papel importante dos próprios pacientes, principalmente aqueles insatisfatoriamente tratados pelos métodos convencionais, em vencer a hesitação dos especialistas em considerar alternativas inovadoras de tratamento de suas doenças.

Temos a convicção de que os TCHT para DAI vão propiciar, em nosso meio, oportunidades valiosas de investigação clínica de vanguarda, beneficiando significativamente um grupo importante de pacientes e expandindo sobremaneira a aplicação dos transplantes de stem cells no país. Para isto, contamos com o indispensável apoio dos colegas transplantadores e dos especialistas em DAI, em suas várias áreas de atuação.

\section{Hematopoietic stem cell transplantation for autoimmune diseases in Brazil}

Júlio C. Voltarelli

\footnotetext{
Abstract

Hematopoietic Stem Cell Transplantation presents a solid basis to be indicated for the treatment of Autoimmune diseases. In this work data related to the procedure and the sequence of events which have contributed to the implantation of a Brazilian protocol are discussed. Included is a discussion of the autogenic procedure using uniform mobilization regimens with Cyclophosphamide $2 g$ $m^{2}$ plus granulocyte-colony stimulation factor and
}

particular conditioning for systemic lupus erythematosus, systemic sclerosis and multiple sclerosis. The formerly described entities were chosen for the beginning of a cooperative protocol after wide-ranging debates which took place both in Ribeirão Preto and San Francisco, USA.

Rev.bras.hematol.hemoter., 2002, 24(1): 9-13

Keywords: Autoimmune diseases, bematopoietic stem cell transplantation, treatment

\section{Referências Bibliográficas}

1. Marmont AM. New horizons in the treatment of severe autoimmune diseases: immunoablation and stem cell transplantation. Ann Rev Med. 2000, 51: 115-134.

2. Tyndall A, Passweg J, Gratwohl A. Hematopoietic stem cell transplantation in the treatment of severe autoimmune diseases. 2000. Ann Rheum Dis 2001. 60: 702-707.

3. Burt RK, Slavin S, Burns WH, Marmont AM. Induction of tolerance in autoimmune diseases by hematopoietic stem cell transplantation: Getting closer to a cure? Blood. 2002, 99:768-784.

4. Tamm M, Gratwohl A, Tichelli A, Perruchoud AP, Tyndall A. Autologous hematopoietic stem cell transplantation in a patient with severe pulmonary bypertension complicating connective tissue disease. Ann Rheum Dis 1996, 55: 779-780.

5. Pasquini R. Transplante de medula óssea em anemias aplásticas. Medicina-Ribeirão Preto. 2000, 33: 219-231.

6. Ferreira E, Ribeiro A, Bacal N, Takatu T, Rosenblit J, Montezuma MP, Pasternak J, Kufner JM, Rosenfeld LG, Sterling L, Hamerschlak M. Transplante de células tronco periféricas autólogas no tratamento de doença autoimune: remissão completa de anemia bemolítica por aglutinina a frio e concomitante vasculite. Bol Soc Bras Hematol Hemoter. 1996, 18 (supl): 191-0.

7. Voltarelli JC e Stracieri AB. Aspectos imunológicos dos transplantes de células- 
tronco hematopoéticas. Medicina-Ribeirão Preto. 2000. 33 :443-462.

8. Traynor AE, Schroeder J, Rosa RM, Cheng D, Stefka J, Mujais S, Baker S, Burt RK. Treatment of severe systemic lupus erythematosus with high-dose therapy and bematopoietic stem cell transplantation: a phase I study. Lancet. 2000. 356: 701.

9. Slavin S. Treatment of intractable multiple sclerosis by re-induction of self tolerance in conjunction with autologous stem cell therapy. Protocol proposal. 1997.

10. Anderlini P, Giralt S, Andersson B et al. Allogeneic stem cell transplantation with fludarabine-based, less intensive conditioning regimens as adoptive immunotherapy in advanced Hodgkin's disease. Bone Marrow Transplant. 2000. 26: 615-620.

11. Comi G, Kappos L, Clanet $\mathrm{M}$ et al. Guidelines for autologous and marrow stem cell transplantation in multiple sclerosis: a consensus report written on behalf of European Group for Blood and MarrowTransplantation and the European Charcot Foundation. J Neurol. 2000. 247: 376-382.

Recebido: 15/12/01

Aceito: 11/02/02 